This item was submitted to Loughborough's Research Repository by the author.

Items in Figshare are protected by copyright, with all rights reserved, unless otherwise indicated.

\title{
Relational coaching in sport: Its psychological underpinnings and practical effectiveness
}

PLEASE CITE THE PUBLISHED VERSION

https://www.routledge.com/Routledge-International-Handbook-of-Sport-Psychology/Schinke-McGannon-

Smith/p/book/9781138022423

\section{PUBLISHER}

Routledge () The Authors

VERSION

AM (Accepted Manuscript)

\section{PUBLISHER STATEMENT}

This work is made available according to the conditions of the Creative Commons Attribution-NonCommercialNoDerivatives 4.0 International (CC BY-NC-ND 4.0) licence. Full details of this licence are available at: https://creativecommons.org/licenses/by-nc-nd/4.0/

\section{LICENCE}

CC BY-NC-ND 4.0

\section{REPOSITORY RECORD}

Jowett, Sophia, and Vaithehy Shanmugam. 2019. "Relational Coaching in Sport: Its Psychological Underpinnings and Practical Effectiveness". figshare. https://hdl.handle.net/2134/28459. 
Jowett, S., \& Shanmugam, V. (2016). Relational Coaching in Sport: Its psychological underpinnings and practical effectiveness. In R. Schinke, K.R.McGannon, B. Smith, Routledge International Handbook of Sport Psychology. Routledge.

\section{CHAPTER FORTY-SEVEN}

\section{Relational Coaching in Sport: Its psychological underpinnings and practical effectiveness.}

Dr Sophia Jowett

School of Sport, Exercise and Health Sciences

Loughborough University

Dr Vaithehy Shanmugam

School of Psychology

University of Central Lancashire

\section{Introduction: Setting the Scene}

Why do some coaches deliver results while others don't quite manage to make their mark? In Europe, an example of extraordinary coaching success is Marcus Weise, field hockey coach maintained his successful streak over the past 10 years or so. His coaching efforts as well as apparent energy and commitment culminated to Gold in Athens 2004 with the German Women’s Olympic hockey team as well as Gold in Beijing 2008 and Gold in London 2012 with the German Men’s Olympic hockey team. He is the only coach to have won gold with a men's and a women's team. In an interview, he was asked how he coaches his athletes and among others he said: that coaching is discovering the capacities and capabilities that his players hide and he went on to say that "when you coach you need to find a door that enables you to get access to the player”. They are so many examples of exceptionally effective and successful coaches, in individual sports (e.g., Toni Minichiello and Jessica Ennis) and team sports (e.g., Alex Ferguson, Jose Mourinho). 
What these extraordinary coaches have in common is their desire and capacity to unlock their athletes’ hidden potential in order to maximise their chances to achieve success. Coaches who believe that their athletes possess more future potential than they presently demonstrate, are more likely to get the best out of their athletes and hence help them succeed. But how can an athlete's hidden potential be released? It can be released when coaches and athletes start to form a genuine working relationship, where they trust, respect, believe, commit and work together toward one goal. This interpersonal connection between the coach and each athlete in the team or squad, often referred to as "relational coaching”, lies at the heart of effective and successful coaching.

\section{Two-Person Relationships at the Heart of Relational Sport Coaching}

To be a technically good coach is one thing, but what gives the coach the "edge" (i.e., the extra effectiveness) in this unforgiving and relentless competitive sport environment, is the connection developed between the coach and athlete (see Figure 1). It is this connection that makes a difference to technical coaching because it supplies coaches with the key to opening the door to their athlete's capabilities, capacities, and potential. The best athletes in the world (following success in World, Olympic Championships) often state that their coaches have been instrumental to their success. In contrast, it is rare to hear athletes who have won gold medals and broken records attacking and criticising their coaches. This is neither random nor coincidental. This unique partnership or relationship developed between a coach and an athlete, we call relational coaching. Relational coaching is the ways coaches and athletes connect to bring about performance success and personal satisfaction.

\section{INSERT FIGURE 1 ABOUT HERE}

Relational coaching emphasises that at the heart of sport coaching lies the interpersonal relationship formed between the coach and every single athlete/member in the squad or the team. Each relationship provides a unique vehicle that allows coaches to 
transform their players by openly communicating about strengths and weaknesses, including individual and joint performance goals. The bond or connection that is formed allows each athlete/player to be more receptive and responsive in the knowledge that their coaches have their best interest at heart. We describe in this chapter how relational coaching is a sound platform from which players develop their skills, techniques, and tactics, and ultimately come closer to reaching their potential.

\section{The Coach-Athlete Relationship Defined and Operationalized}

'Relationship' is a term that, because it is so common, we take its meaning for granted. We know that relationships are important because they can bring great happiness and a sense of reward but they can also bring sadness. We also know that relationships are not easy; they are difficult to manage and as complex to understand as the people comprising them. Nonetheless, it is important to define the meaning of relationships. The coach-athlete relationship has been defined as the situation in which coaches and athletes' feelings, thoughts and behaviours are mutually and causally interconnected (Jowett, 2007). Over the past 15 years we have studied in depth the content, quality and functions of the coach-athlete relationship. We interviewed hundreds and collected quantitative data from thousands of coaches and players (in a range of sports) about their thoughts of what is the relationship, what are its main ingredients or characteristics, and what is the role and significance of this relationship for skill development and performance as well as psychosocial development and wellbeing (e.g., Jowett, 2003; Jowett \& Cockerill, 2003; Jowett \& Frost, 2007; Jowett \& Meek, 2000; Jowett \&TimsonKatchis, 2005; Jowett, Timson-Katchis, \& Adams, 2007). We found that there are four key properties that correspond with the definition's main characteristics of the interdependence of coaches and athletes' feelings, thoughts and behaviours:

1. Closeness reflects the affective bond developed between coaches and athletes and is manifested in mutual trust and respect, emotional caring and support, as well as interpersonal 
liking and appreciation. Affective closeness was thought of as the bedrock of the sporting partnership.

2. Commitment reflects the intentions of coaches and athletes to maintain a bond or a connection that is both close and long-term. This long-term orientation toward the relationship is considered important as it takes time to develop skill and bring about success. 3. Complementarity reflects coaches and athletes' behaviours that are complementary or cooperative. Accordingly, there are two sets of complementary behaviours that coaches and athletes show on the pitch: (a) corresponding refers to the same behaviours that the coach and the athlete are expected to display in training and competition such as, responsiveness and openness (see Jowett \& Ntoumanis 2004); (b) reciprocal refers to different behaviours that the coach and the athlete are expected to display in training and competition such as, when the coach directs or instructs and the athlete follows or executes instructions in training (see Yang \& Jowett, 2013). These two sets of behaviours are thought to determine the efficient conduct of interactions between coaches and athletes.

4. Co-orientation reflects coaches and athletes' co-orientated or interdependent feelings, thoughts, and behaviours and highlights the degree to which coaches and athletes have a common ground (i.e., they are on the same page) about the nature of their sporting partnership.

These 4 key relational constructs are said to define the quality of the sporting relationship between the coach and each performer in a squad or a team. These properties are known as the $3+1$ Cs of the coach-athlete relationship. Relationships that possess such properties are said to influence and be influenced by a number of factors including individual difference characteristics (e.g., age, gender, personality) as well as social-cultural (e.g., race/ethnicity, culture, language, sport type) and relationship (e.g., typical versus atypical relationships, length of relationships) factors (see Figure 2). 


\section{INSERT FIGURE 2 ABOUT HERE}

\section{Assessing the Coach-Athlete Relationship Quality}

A fundamental tenet of model or theory construction is that it must be testable (Bacharach, 1989). Thus, a proposal of any theory or model should be accompanied by suggestions concerning measurement of its main constructs. The measurement of the 4Cs has been achieved through the development of Coach-Athlete RelaTionship Questionnaires (CART-Q). The CART-Q was originally developed to measure coaches and athletes' direct perceptions of closeness (e.g., “I trust my coach/athlete”), commitment (e.g., "I am committed to my coach/athlete”) and complementarity (e.g., When I am coached by my coach/When I coach my athlete, I am responsive to his/her efforts”) (Jowett \& Ntoumanis, 2004). Subsequently, a corresponding questionnaire was developed to measure coaches and athletes’ metaperceptions of closeness (e.g., My coach/athlete trusts me”), commitment (e.g., “My coach/athlete is committed to me”) and complementarity (e.g., "My coach/athlete is responsive to my efforts”) (Jowett, 2009). These psychometric studies have highlighted the items comprising the CART-Q to possess sound properties of validity and reliability. These scales have also been translated and validated in Flemish (Balduck \& Jowett, 2010), French (Nicolas, Jowett, \& Yang, 2015), Chinese (Yang \& Jowett, 2010), and Arabic (Ahmad, 2014). In a recent validation study, the direct perspective of the CART-Q was found to be invariant across different languages/cultures (Belgium, China, Greece, Spain, Sweden, UK and US) (see Yang \& Jowett, 2012). The CART-Q has provided an impetus for research and for the generation of valuable theoretical knowledge and practical understanding in the area of coach-athlete relationships.

\section{Overview of Research on Coach-Athlete Relationship}

This section selectively presents research that has been based on the $3+1 \mathrm{Cs}$ model and used the CART-Q to investigate antecedent and consequent variables of the quality of the coach- 
athlete relationship. A number of studies have been conducted to assess whether the coachathlete relationship associates with different facets of satisfaction. Satisfaction has been the focus of a series of studies because individuals who are satisfied and happy, as opposed to dissatisfied and unhappy, are more likely to be persistent in good and bad times, choose more challenging activities, and generally desire to accomplish in the life domains that matter to them (cf. Michalos, 1980). Collectively, this research suggests that the better the quality of the coach-athlete relationship, the more satisfied athletes and coaches are with the coaching relationship (Davis, Jowett, \& Lafraniere, 2013; Jowett \& Ntoumanis, 2004; Lorimer, 2009), as well as with performance, training and coach treatment (e.g., Jowett, 2009; Jowett, Shanmugam, \& Caccoulis, 2012). Moreover, research findings indicate that the association between relationship quality and different facets of satisfaction is moderated by coaches and athletes’ relationship length, performance levels, and dyads' gender composition (Jowett \& Nezlek, 2012). Specifically, the longer the coaching relationship, the higher the level of performance, and same-gender dyads are likely to feel more satisfied, because they have better and stronger coach-athlete relationships. Correspondingly, research has shown that athletes who participate in individual sports are likely to be more satisfied than athletes who participate in team sports, because they seem to have developed relationships that are more close, committed, and complementary with their coaches (Rhind, Jowett, \& Yang, 2012).

One of the mechanisms that would seem to mediate or explain the link between the quality of the coach-athlete relationship and positive outcomes such as satisfaction is the fulfilment of the three basic psychological needs of autonomy, competence and relatedness) (Deci \& Ryan, 2000). For example, Riley and Smith (2011) found that the three basic psychological needs partially mediated the association between perceived coach-athlete relationship and self-determined motivation in a sample of young basketball players (12-15 years of age). Subsequently, Felton and Jowett (2013) found that athletes' perceptions of both 
coach-athlete relationship quality and coach autonomy supportive behaviours led athletes feeling skilful and competent and in turn feeling a sense of vitality, vigour, energy and liveliness when the basic need of competence (feeling capable, skilled and experienced) was satisfied. However, they also found that the need of competence explained the association between athletes' perceptions of coach controlling behaviour and negative affect. This finding highlights that athletes are less likely to satisfy the need of competence within a coaching context where coaches are employing behaviours that are controlling and generally negative. Coach controlling behaviours are also likely to make athletes feel afraid, upset, nervous and hostile (see also Bartholomew, Ntoumanis, \& Thogersen-Ntoumani, 2011; Felton \& Jowett, 2015). A series of studies have highlighted that better quality coaching relationships associate with effective coaching behaviours. For example, Olympiou, Jowett, and Duda (2008) found that athletes who had relationships with their coaches that were characterised by high levels of trust and respect, co-operation and commitment, perceived their coaches as being more task-orientated focusing on athletes' learning and developing skills as opposed to outperforming competitors. Similarly, Michel, Jowett, and Yang (2015) found that athletes' high levels of closeness and commitment were better predictors of a range of positive coaching behaviours concerning physical preparation, skill development and goal setting; whereas low levels of negative coaching behaviours such as friction and discord were negatively associated with relationship quality. One explanation for these findings was that when athletes bond with, and commit to their coaches, coaches may then feel duty-bound, obliged or even compelled to reciprocate similar positive interpersonal behaviours (e.g., high levels of instruction, feedback, attentiveness, approachability). The maxim "one should treat others as one would like others to treat oneself" seems to be supported here. Moreover, the findings of this study would seem to suggest that not only coaches but also athletes would benefit from recognising the role and significance of 
harmonious and stable coach-athlete relationships. Athletes who have the skills to connect with their coaches effectively by displaying positive interpersonal behaviours, feelings and thoughts are more likely to elicit from coaches their best behaviours and practises and thus benefit the most from them. The coach-athlete relationship has also been associated with perceptions of self. For example, Jowett (2008) has found that academy athletes (selected/identified as talented) who had an established relationship (>3 years) with their coach not only perceived higher levels of closeness, commitment and complementarity but also felt more competent, skilled, and capable than academy athletes who did not have an established relationship ( $<3$ years) with their coach. This finding suggests that longer relationships allow coaches and athletes to get to know one another and on that basis develop solid and more successful partnerships. In a different yet related study, Jackson, Grove and Beauchamp (2010) found that different types of efficacy beliefs (self/other-efficacy and relation-inferred self-efficacy) predicted the quality of the coach-athlete relationship. For instance, a high degree of confidence in the other person's (coach/athlete) capabilities predicted perceptions that the relationship will be both close and long-term. However, these associations were moderated by the role held by each member in the relationship. Stronger associations or predictions between efficacy beliefs and relationship quality were found for athletes than for coaches.

The quality of the coach-athlete relationship has also been found to be capable to predict important group variables such as team cohesion (a sense of belongingness in the group) and collective efficacy (a sense of being valuable and effective as a collective) (see Jowett, Shanmugam, \& Caccoulis, 2012). For example, athletes’ perceptions of their relationship with the coach has been found to add to the prediction of team cohesion and collective efficacy beyond what is predicted by perceptions of coach leadership alone (e.g., Hampson \& Jowett, 2014). Moreover, coach leadership and coaching relationship variables 
together were shown to be better and stronger predictors of task cohesion than social cohesion (Jowett \& Chaundy, 2004). In another study, Vella, Oades, and Crowe (2013) found that the best predictor of developmental experiences (personal and social skills, cognitive skills, goal setting, initiative, and negative experiences) is a combination of coach transformational leadership behaviour (individual consideration, intellectual stimulation, and appropriate role modelling) and the quality of the coach-athlete relationship. It would appear that coach leadership and coaching relationships act synergistically. It is possible that coach leadership involves social influences that transpire in the coach-athlete relationship. Thus, while coach leadership is important, effective coach-athlete relationship may give coaches the advantage when the aim is building cohesive and efficacious teams.

Athletes' motivation is central to talent development as competitive sport in which these talented athletes operate is an unforgiving, intense and volatile environment. Athletes' motivation, perseverance, resilience and patience are without a doubt challenged over the course of their athletic development and growth. Applying Andrew Elliot's (1999) hierarchical model of approach and avoidance motivation, Adie and Jowett's (2010) findings highlighted that when athletes’ perceive their coaches to be affectively connected, think that the relationship will last and interact co-operatively with one another, then they are more intrinsically motivated because they can fully focus on striving for task mastery and personal improvement in the knowledge that their coach is on their side or has their best interest at heart. They also found athletes' on-going concerns about the relationship quality reflected in coaches' absence of long-term support (perceptions of coaches' commitment to athletes), appreciation and respect (perceptions of closeness), openness and accessibility (perceptions of complementarity), disrupted their concentration away from competence-based pursuits and reoriented it toward the possibility of failure. Hence stable and harmonious as opposed to unstable and discordant relationships may promote and sustain athletes' intrinsic motivation 
through the adoption of mastery approach goals. On a different yet related note, coaches’ motivation for coaching has been found to be augmented when coaches are satisfied with the quality of the coach-athlete relationship (Jowett, 2008). Thus, high quality coach-athlete relationship can act as a motivational and driving force for both relationship members.

Research has also informed that athletes' passion for their sport is linked with their perceived quality of the coach-athlete relationship. Based on Vallerand's (2007) dualistic model of passion for an activity, peoples’ passion can take two forms: (a) harmonious passion for an activity refers to a strong desire to freely and autonomously engage in the activity one loves, and (b) obsessive passion for an activity refers to a strong desire to engage in the activity but it is the activity that controls and compels the person to engage and not the other way around; these individuals feel pressurised to participate in. Lafraniere, Jowett, and Vallerand (2008) found that harmoniously passionate athletes were highly interdependent with their coaches in terms of closeness, commitment and complementarity. However, it was also found that obsessively passionate athletes were committed to their coach (direct perspective), even when they viewed their coach as being uncooperative (meta perspective). According to the dualistic model of passion, obsessive passion can lead to rigid persistence and in this study obsessive passion led the athletes committing to a relationship that was perceived to be less than optimal. This study highlighted that obsessive passion can lead to persistence in a coach-athlete relationship even though negative consequences can be derived from it. Overall, these findings demonstrated that harmonious passion positively predicts high-quality coach-athlete relationship, whereas obsessive passion was predictive of a lessthan-optimal coach-athlete relationship

In a dyadic research design, Lafraniere, Jowett, Vallerand, and Carbonneau (2011) found that harmonious passionate coaches were more likely to manifest autonomy supportive coaching behaviours involving taking their athletes’ perspective into account, providing their 
athletes with a rationale for tasks, and encouraging self-initiative from athletes while obsessive passionate coaches were more likely to manifest negative, controlling and intimidating coaching behaviours. In turn, coaches’ perceptions of autonomy-supportive coaching behaviors were found to predict athletes’ perceptions of high quality coach-athlete relationships possibly because athletes who feel cared for, understood and respected by their coach are more inclined to invest time and energy to develop positive and strong bonds with their coach. In addition, results showed that high quality coach-athlete relationships were beneficial to athletes’ happiness. In contrast, coaches' obsessive passion positively predicted controlling coaching behaviours toward their athletes possibly because they are more egoinvolved within coaching. Moreover, coaches’ controlling behaviours were negatively but non-significantly related to athletes’ perceived relationship quality. It was explained that within the coach-athlete relational context authority may be well defined and potentially accepted. Both coaches and athletes have specific roles to accomplish (see e.g., Yang \& Jowett, 2013). Thus, athletes may expect their coaches to be in charge, lead, direct, and make decisions (Jowett \& Carpenter, 2004). Coaches may therefore be presumed by athletes to be authoritative and this could explain why controlling behaviour was unrelated to relationship quality. Consequently, controlling behaviours emitted by coaches could be perceived by athletes as not revealing much about how coaches respect, care for, and understand their athletes. Future research is needed in order to further explore this hypothesis. More recently, we started investigating how personality or enduring personality orientations such as Big Five personality factors (Costa \& McCrae, 1992) and attachment styles (Bowlby, 1973) influence coaches and athletes perceptions of the quality of the coach-athlete relationship. For example, Jowett and her colleagues found that athletes' personality factor of agreeableness (tendency to co-operate, reassure, trust and understand others) positively predicted athletes’ perceptions of good quality relationships with their coaches (Jowett, Yang, 
\& Lorimer, 2012). In a dyadic research design, Yang, Jowett, and Chan (2015) found that such personality factors as neuroticism (tendency to experience negative emotions, such as anger, anxiety, or depression; emotional instability) and conscientiousness (tendency to show self-discipline, act dutifully, and aim for achievement against measures or outside expectations) predicted one’s own perceptions of relationship quality negatively and positively respectively. In a similar vein, Jackson, Dimmock, Guicciardi, and Grove (2010) found that that personality factors such as agreeableness, extroversion, and conscientiousness predicted coaches and athletes' commitment (e.g., dedicated to the coach/athlete and keeping the relationship going over time) and closeness (e.g., mutual trust, feeling friendly and feeling close as opposed to distant). Moreover, this study highlighted that dissimilarity in coaches and athletes' personality may undermine perceptions of the coach-athlete relationship quality. It is important to point out that although the CART-Q was not used in this study to measure the quality of the coach-athlete relationship the modified assessment tools used in their study were very similar to what the CART-Q measures in terms of closeness and commitment. What is most informative from this research is that athletes’ personality factors were also predictive of coaches' perceptions of relationship quality (Yang et al., 2015). These partner effects were supported in another research. Davis et al. (2013) found that athletes' avoidant attachment style (no evident affective or otherwise attachment, distant and inexpressive) not only influenced their own relationship quality negatively but that of coaches too. It is plausible that athletes' negative personality characteristics may have the capacity to "disrupt" their coaches' role or better judgement to successfully provide the support, guidance, and instruction needed in order for these athletes to acquire new skills and improve performance. The findings from this study and from that conducted by Yang et al., 2015 raise the question “why do coaches’ personality not have the capacity to affect their athletes’ perception of relationship quality (be it positively or negatively)?” One reason for this may be found in the 
specific and often rather distinct roles coaches and athletes are expected to play within their dyadic coach-athlete relationship In the coach-athlete relationship, the coach is commonly the experienced and the athlete is commonly the inexperienced who needs the encouragement to take on new challenges, and the support and guidance to deal with challenges in the face of adversity (e.g., Côté \& Fraser-Thomas, 2007; Jackson, Grove, \& Beauchamp, 2010; Jowett, 2005; Yang \& Jowett, 2013). In light of this, the coach’s effective execution of his or her role (how does the coach coach?) as well as experience, reputation, and qualification, may be far more important for athletes than his/her personality and its manifestations (what is a coach's personality?) when it comes to evaluating the quality of the relationship. This conjecture warrants further investigation. Taken together the findings of these studies seem to suggest that while athletes' perceptions of relationship quality are likely to remain unaffected by coaches' personality orientations, coaches' perceptions of relationship quality are likely to be affected by their athletes' personality orientations (e.g., neuroticism, consciousness, avoidant attachment style). This finding has enormous applications for coaching. While there are many definitions of sport coaching (see Côté \& Gilbert, 2009), all agree that effective sport coaching is a fair, considerate, caring and helping practice/process where the focus is on maximising athletes’ potential. However coaches’ duty of care, responsibility and obligation may be affected because of perceptions of their athletes’ personality. Athletes with neurotic personality (Yang et al., 2015) and insecure attachment styles (Davis et al., 2013) may be viewed less favourably by coaches (Felton \& Jowett, 2015). Thus, coaches need to be better equipped to work effectively and efficiently with athletes whose personalities may be less desirable or more difficult to work with.

The findings of a number of studies have also highlighted the central role of empathy in explaining the association of the quality of the coach-athlete relationship and important outcomes such as training and performance. Jowett et al. (2012) found that athletes' 
perceptions of their coaches' empathy reflected in the coaches' understanding of their athletes' feelings and thoughts explained the association between relationship quality (as defined by the 3Cs) and satisfaction with training and instruction. They explained that athletes who feel that their relationships with the coach is underlined by connection, long-term orientation, and co-operation are more likely to be satisfied with training because they feel that their coaches are attune with, sensitive and thus more knowledgeable of what is needed to improve performance. Moreover, Lorimer and Jowett (2009a) found that coaches’ empathic accuracy (understanding accurately athletes’ feelings and thoughts) was lower when working with larger groups of athletes and, that coaches in individual sports displayed greater accuracy than coaches in team sports. They also found coaches in individual sports address more often the individual athlete while coaches in team sports address the team or group - the former promoted "shared cognitive focus" (similarity of thoughts and feelings during each interaction). In fact, it was found that shared cognitive focus or simply being on the "same wavelength” is the function of similarity assumed (co-orientation) by relationship members (Lorimer \& Jowett, 2011). They also found that coaches whose training sessions were longer demonstrated increased empathic accuracy. In another study, Lorimer and Jowett (2009b) found that empathic accuracy (understanding one another) was predictive of both relationship quality and satisfaction with training. This would seem to indicate that increased empathic accuracy can lead to positive relational outcomes and therefore a more successful coachathlete relationship. Lastly, this line of research has also identified that female coaches were more empathically accurate than male coaches (Lorimer \& Jowett, 2010). In terms of athletes, it was found that the highest accuracy scores were displayed by female athletes working with male coaches. While research outside the realm of sport has shown that empathic accuracy may be largely unrelated to gender, it has also shown that empathic accuracy may be a function of people's motivation to understand others (Ickes, Gesn, \& Graham, 2000) or roles 
people assume in a dyadic relationship. For example, Snodgrass (1992) revealed that within a leader-subordinate relationship, subordinates were more sensitive to how their leaders felt about them (the subordinates), and leaders were more sensitive to how their subordinates felt about themselves. Thus, one way to understand Lorimer and Jowett's (2010) results may be that athletes and coaches are motivated to understand as accurately as possible one another for a number of reasons (e.g., accuracy validates their physical concept/looking-glass-self phenomenon, encourage them to continue strive, helps them to know the other to achieve goals). Athletes and female athletes specifically may also feel that as subordinates their role is to follow, understand and accept coaches' instructions, opinions and feedback. In the coach-athlete relationship, if we assume that athletes take up a subordinate role being empathically accurate with their coach may promote a sense of empowerment, which can be useful for both the athlete (and the coach).

Collectively, the results of these studies are valuable because (a) they underline the power of the relationship for athletes and coaches' development and success; and (b) they inform better coaching practice that are relational in nature. We all, to some degree, have witnessed coaching that can either make or break sport performers and thus ensuring its quality is paramount.

\section{Nurturing the Coach-Athlete Relationship Through Relational Coaching}

The quality of relational coaching is one of these active environmental factors that can have significant effects on athletes’ developmental trajectory in the sport. While coaches cannot change the genetic make-up of their athletes, what they can change is the environment in which these athletes train, with the ultimate goal to succeed - regardless of how one chooses to define success. One way to enhance the effectiveness of coaching is to promote the development and maintenance of good coach-athlete relationships. Since good quality relationships are found to be negatively associated with interpersonal conflict (e.g., 
disagreements, misunderstandings, dislikes; Jowett, 2009), one way to develop and maintain relationships as well as alleviate the potential negative effects of interpersonal conflict is via communication. It was mentioned earlier in the chapter that if one views the relationship as a vehicle moving its passengers, coach and athlete, from place A to B (better place), communication is the fuel that keeps the relationship going by powering, activating, energising and driving it. COMPASS is a communication model that has recently been developed to highlight key strategies that coaches and athletes use or can use to develop better relationships (see Rhind \& Jowett, 2010, 2011):

- Conflict management - reflects efforts to identify, discuss, resolve and monitor potential areas of disagreement or misunderstanding before they escalate

- Openness - includes efforts to engage in open lines of communication

- Motivation - highlights efforts from both parties to make a partnership that is rewarding, active, ambitious, and energetic

- Preventative - underlines efforts to discuss expectations, rules, roles and what should happen if these are not met

- Assurance - includes showing one's commitment to the relationship (making sacrifices that will assist the relationship to be functional and successful)

- Support - is reflected in helping one another (the coach or athlete) through difficult times

- Social networks - the relationship built between the coach and the player is not disconnected from other relationships and people; subsequently, creating of opportunities to develop strong bonds with others is paramount to the success of the relationship.

Rhind and Jowett (2012) have shown that coach-athlete partnerships that lacked in closeness (e.g., mutual respect, trust, interpersonal like) were likely to benefit from utilising such 
strategies as open dialogue, disclosing of information (openness) and working towards developing a close-nit network of individuals (e.g., parents, teammates) around the relationship members (social networks). While the utilisation of motivational, assurance and support strategies were likely to allow coaches and athletes to increase commitment via setting short- and long-term goals, as well as creating an environment in which a sense of care and support was evidenced. Conflict management and preventive relationship strategies seemed to be beneficial when levels of complementarity or co-operation were low. Thus, by identifying, resolving and monitoring conflictual issues (conflict management) and setting up a contract of expectations (prevention), complementarity or co-operation was expected to increase. Based on COMPASS, Table 1 draws on specific examples of interpersonal behaviours coaches maybe benefit employing in training and competition to nurture a relational coaching environment. Future research is warranted to test whether the dimensions of COMPASS can form an effective intervention to promote better quality coach-athlete relationships.

INSERT TABLE 1 about here

\section{Concluding Remarks}

In sport, it takes two to bring about change such as skill development and performance success. Neither the coach nor the athlete can do it alone! Subsequently, the dyadic relationship that unites them has the capacity to become key in athletes' and coaches' journey to realizing their full potential. Relational coaching underlines the importance of this and emphasises that coaches and athletes together are responsible for performance success and personal satisfaction. Relational coaching is reflected in the harmonious and stable relationships coaches and athletes/players form and once these are maintained over time, the journey to skill development and performance success is more likely to become a personally fulfilling venture. The increased interest in and importance placed on developing world class 
sport performances in the UK and elsewhere necessitates research attention to factors that can help support the developing athlete. Our research indicates that relational coaching as this emerges through the coach-athlete relationship and communication is a significant factor for increased and continuous sport participation that is both successful and rewarding for both the coach and the athlete. 


\section{References}

Adie, J. W., \& Jowett, S. (2010). Meta-perceptions of the coach-athlete relationship, achievement goals, and intrinsic motivation among sport participants. Journal of Applied Social Psychology, 40, 2750-2773.

Ahmad, H. (2014). The coach-athlete relationship in the Middle East: Cultural considerations. Unpublished PhD Thesis. Loughborough University.

Backarach, S. B. (1989). Organisational theories: Some criteria for evaluation. Academy of Management Review, 14, 496-515.

Balduck, A. L., \& Jowett, S. (2010). Psychometric properties of the Belgian coach version of the coach-athlete relationship questionnaire (CART-Q). Scandinavian Journal of Medicine and Science in Sports, 20, 779-786.

Bartholomew, K., Ntoumanis, N., \& Thogersen-Ntoumani, C. (2011). Self-determination theory and the darker side of athletic experience: The role of interpersonal control and need thwarting. Sport and Exercise Psychology Review, 7, 23-27.

Bowlby, J. (1973). Separation: anxiety and anger. [vol. 2 of Attachment and loss]. London: Hogarth Press.

Costa, P. T. Jr., \& McRae, R. R. (1992). Revised NEO Personality Inventory (NEO-PI-R) and NEO Five-Factor Inventory (NEO-FFI) professional manual. Odessa, Florida: Psychological Assessment Resources, Inc.

Côté, J., \& Gilbert, W. (2009). An integrative definition of coaching effectiveness and expertise. International Journal of Sports Science \& Coaching, 4, 307-323.

Côté, J, \& Fraser-Thomas, J. (2007). Youth involvement in sport. In P. R. E. Crocker (Ed.), Introduction to sport psychology: A Canadian perspective (pp. 266-294). Toronto: Pearson Prentice Hall. 
Davis, L., Jowett, S., \& Lafrenière, M-AK. (2013). An attachment theory perspective in the examination of relational processes associated with coach-athlete dyads. Journal of Sport and Exercise Psychology, 35, 156-167.

Deci, E. L., \& Ryan, R. M. (2000). The “what” and “why” of goal pursuits: Human needs and the self-determination of behavior. Psychological Inquiry, 11, 227-268.

Elliot, A.J. (1999). Approach and avoidance motivation and achievement goals. Educational Psychologist, 34, 149-169.

Felton, L., \& Jowett, S. (2013). "What do coaches do" and "how do they relate”: Their effects on athletes’ psychological needs and functioning. Scandinavian Journal of Medicine and Sports Sciences, 23, 130-139.

Felton, L., \& Jowett, S., (2015). On understanding the role of need thwarting in the association between athlete attachment and well/ill-being. Scandinavian Journal of Medicine and Sports Sciences, 25, 289-298.

Hampson, R., \& Jowett, S. (2014). Effects of coach leadership and coach-athlete relationship on collective efficacy. Scandinavian Journal of Medicine \& Science in Sports, 24, 454460.

Ickes, W., Gesn, P. R., \& Graham, T. (2000). Gender differences in empathic accuracy: Differential ability or differential motivation? Personal Relationships, 7, 95-109. Jackson, B., Grove, J. R., \& Beauchamp, M. R. (2010). Relational efficacy beliefs and relationship quality within coach-athlete dyads. Journal of Social and Personal Relationships, 27, 1035-150.

Jackson, B., Dimmock, J., Gucciardi, D., \& Grove, J. (2010). Relationship commitment in athletic dyads: Actor and partner effects for big five self-and-other ratings. Journal of Research in Personality, 44, 641-648. 
Jowett, S., \& Meek, G.A (2000). The coach - athlete relationship in married couples: An exploratory content analysis. The Sport Psychologist, 14, 157-175.

Jowett, S. (2003). When the honeymoon is over: A case study of a coach - athlete relationship in crisis. The Sport Psychologist, 17, 444-460.

Jowett, S. (2005). Partners on the sport field: The coach-athlete relationship, The Psychologist, 18, 412-415.

Jowett, S. (2007). Interdependence analysis and the $3+1$ Cs model in the coach-athlete relationship. In S. Jowett \& D. Lavallee (Eds.), Social psychology in sport (pp. 15-27). Champaign, IL: Human Kinetics.

Jowett, S. (2008). Moderators and mediators of the association between the coach-athlete relationship and physical self-concept. International Journal of Coaching Science, 2, 43-62.

Jowett, S. (2009). Validating the coach athlete relationship measures with the nomological network. Measurement in Physical Education and Exercise Science, 13, 34-51.

Jowett, S., \& Carpenter, P. (2004). Coaches' and athletes’ perceptions of rules in the coachathlete relationship. In poster presented at the annual conference of the Association of the Advancement of Applied Sport Psychology, Minnesota, USA, October.

Jowett, S., \& Chaundy, V. (2004). An investigation into the impact of coach leadership and coach - athlete relationship on group cohesion. Group Dynamics: Theory, Research and Practice, 8, 302-311.

Jowett, S., \& Cockerill, I. M. (2003). Olympic Medallists' perspective of the athlete - coach relationship. Psychology of Sport and Exercise, 4, 313-331.

Jowett, S., \& Frost, T.C. (2007). Race/Ethnicity in the all male coach-athlete relationship: Black footballers' narratives. Journal of International Sport and Exercise Psychology. 3, 255-269. 
Jowett, S., \& Nezlek, J. (2012). Relationship interdependence and satisfaction with important outcomes in coach - athlete dyads. Journal of Social and Personal Relationships, 29, 287-301.

Jowett, S., \& Ntoumanis, N. (2004). The Coach-Athlete Relationship Questionnaire (CART Q): Development and initial validation. Scandinavian Journal of Medicine and Science in Sports, 14, 245-257.

Jowett, S., \& Timson-Katchis, M. (2005). Social networks in sport: The influence of parents on the coach-athlete relationship. The Sport Psychologist, 19, 267-287.

Jowett, S., Timson-Katchis, M., \& Adams, R. (2007). Too close for comfort? Dependence in the dual role of parent/coach-child/athlete relationship. International Journal of Coaching Science, 1, 59-78.

Jowett, S., Shanmugam, V., \& Caccoulis, S. (2012). Collective efficacy as a mediator of the link between interpersonal relationships and athlete satisfaction in team sports. International Journal of Sport and Exercise Psychology, 10, 66-78.

Jowett, S., Yang, X. S., Lorimer, S. (2012). The Role of Personality, Empathy, and Satisfaction within the Context of the Coach-Athlete Relationship. International Journal of Sports Coaching, 6 (2), 3-20.

Lafrenière, M.-A.K., Jowett, S., Vallerand, R. J., \& Carbonneau, N. (2011). Passion for coaching and the quality of the coach-athlete relationship: The mediating role of coaching behaviors. Psychology of Sport and Exercise, 12, 144-152.

Lafreniere, M.-A. K., Jowett, S., Vallerand, R. J., Donahue, E. G., \& Lorimer, R. (2008). Passion in sport: On the quality of the coach-player relationship. Journal of Sport and Exercise Psychology, 30, 541-560.

Lorimer, R. (2009). Coaches’ satisfaction with their athletic partnerships. International Journal of Coaching Science, 3, 55-64. 
Lorimer, R., \& Jowett, S. (2009a). Empathic accuracy in coach-athlete dyads who participate in team and individual sports. Psychology of Sport and Exercise, 10, 152-158.

Lorimer, R., \& Jowett, S. (2009b). Empathic accuracy, meta-perspective, and satisfaction in the coach-athlete relationship. Journal of Applied Sport Psychology, 21, 201-212.

Lorimer, R., \& Jowett, S. (2010). The influence of role and gender in the empathic accuracy of coaches and athletes. Psychology of Sport and Exercise, 11, 206-211.

Lorimer, R., \& Jowett, S. (2011). Empathic accuracy, shared cognitive focus, and the assumptions of similarity made by coaches and athletes. International Journal of Sport Psychology, 41, 40-49.

Michalos, A. C. (1980). Satisfaction and happiness. Social Indicators Research, 8, 385-422.

Nicolas, M., Jowett, S., \& Yang, S. (2015). Coaching relationships and coaching behaviours: What is the link? Manuscript under review.

Olympiou, A., Jowett, S., \& Duda, J. L. (2008). The psychological interface between the coach-created motivational climate and the coach-athlete relationship in team sports. The Sport Psychologist, 22(4), 423-438.

Rhind, D. J. A., \& Jowett, S. (2010). Relationship maintenance strategies in the coach-athlete relationship: The development of the COMPASS model. Journal of Applied Sport Psychology, 22, 106-121.

Rhind, D. J. A., \& Jowett, S. (2011). Linking maintenance strategies to the quality of coachathlete relationships. International Journal of Sport Psychology, 42, 55-68.

Rhind, D., \& Jowett, S. (2012). Development of the Coach-Athlete Relationship Maintenance Questionnaire (CARM-Q). International Journal of Sports Science and Coaching, 7(1), 121-137. 
Rhind, D., Jowett, S., \& Yang, S. (2012). A comparison of athletes' perceptions of the coachathlete relationship in team and individual sports. Journal of Sport Behavior, 35, 433441.

Riley, A., \& Smith, A.L. (2011). Perceived coach-athlete and peer relationships of young athletes and self-determined motivation for sport. International Journal of Sport Psychology, 42, 115-133.

Snodgrass, S. E., (1992). Further effects of role versus gender on interpersonal sensitivity. Journal of Personality and Social Psychology, 62, 154-158.

Vella, S. A., Oades, L. G., \& Crowe, T. P. (2013). The relationship between coach leadership, the coach-athlete relationship, team success, and the positive developmental experiences of adolescent soccer players. Physical Education and Sport Pedagogy, 18, 549-561.

Vallerand, R.J. (2007). Passion for sport in athletes. In S. Jowett \& D. Lavallee (Eds.), Social psychology in sport (pp. 249-264). Champaign, IL: Human Kinetics.

Yang, S. X., \& Jowett, S. (2010). Validation of the Chinese version of the Coach-Athlete Relationship Questionnaire (CART-Q): Factorial and concurrent validity. International Journal of Coaching Science, 4, 73-89.

Yang, S. X., \& Jowett, S. (2012). Psychometric properties of the Coach-Athlete Relationship Questionnaire (CART-Q) in seven countries. Psychology of Sport and Exercise, 13, 3643.

Yang, X. S., \& Jowett, S. (2013). Conceptual and measurement issues of the complementarity dimension of the coach-athlete relationship across cultures. Psychology of Sport \& Exercise, 14, 830-841. 
Yang, S. X., Jowett, S., \& Chan, D. K. (2015). Effects of Big-Five Personality Traits on the Quality of Relationship and Satisfaction in Coach-Athlete Dyads. Scandinavian Journal of Medicine and Science in Sports. (available on line) 
Figure 1. Ingredients of Effective and Successful Coaching

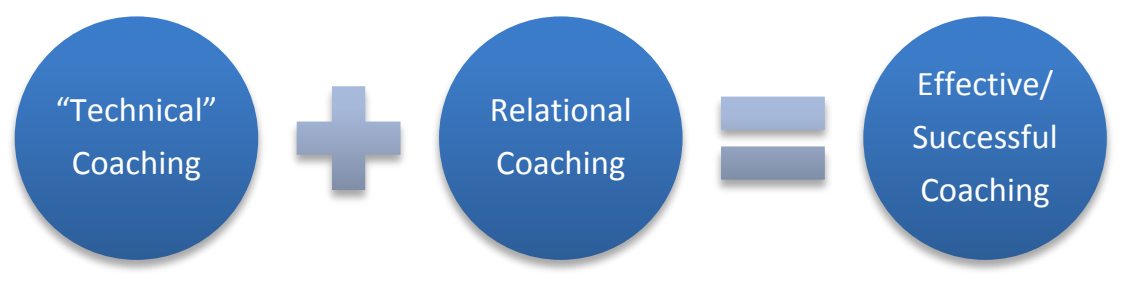

Figure 2. Antecedents and consequences of the quality of the coach-athlete relationship (adapted from Jowett \& Poczwardowski, 2007).

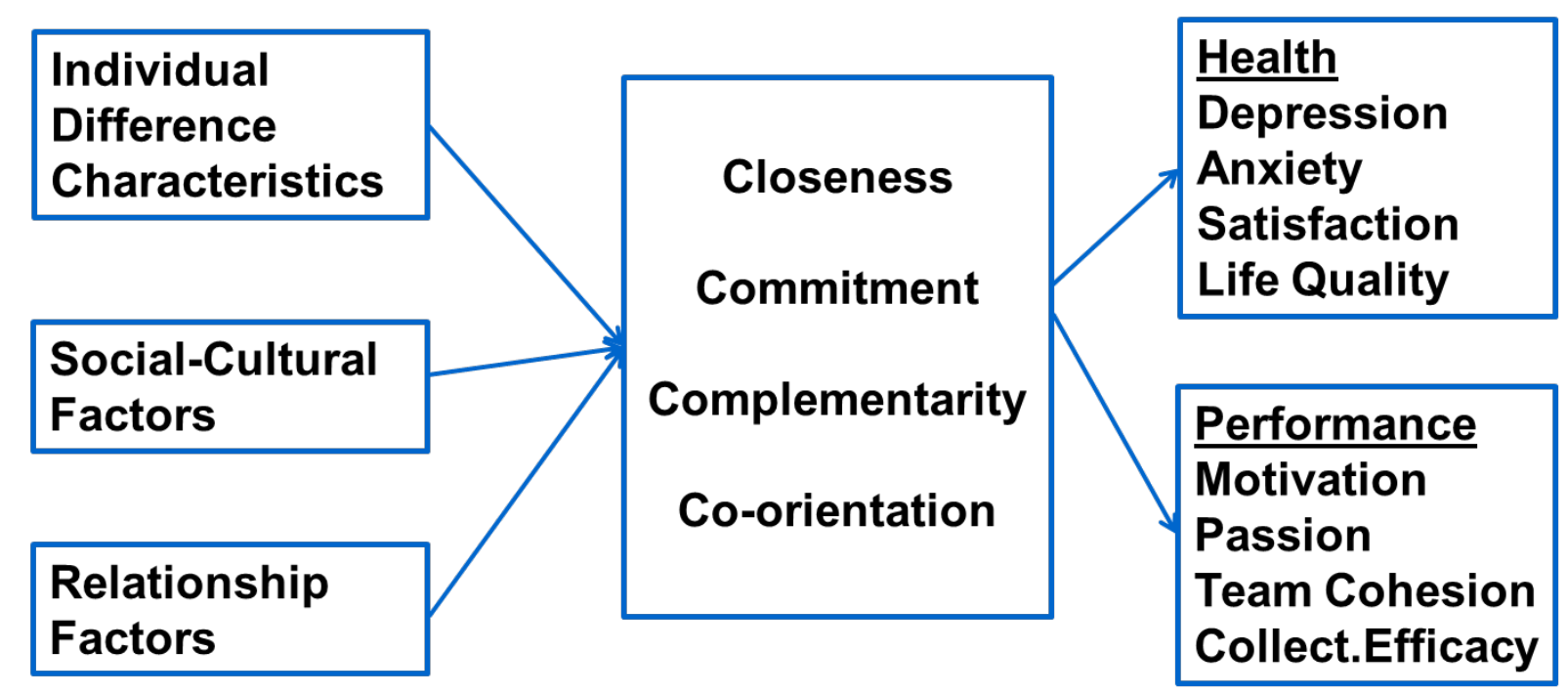


Table 1. Ways to Create a Relational Coaching Environment

\begin{tabular}{|c|c|c|}
\hline Creating Closeness & Creating Commitment & reating Complementarity \\
\hline $\begin{array}{l}\text { - Being open - offer } \\
\text { information, show you } \\
\text { have nothing to hide, don't } \\
\text { omit, mask; openness is } \\
\text { reciprocated } \\
\text { - Keeping confidences - } \\
\text { keep secrets imparted to } \\
\text { you. No gossip is allowed. } \\
\text { NEVER blab someone } \\
\text { else's story. } \\
\text { - Display loyalty - protect } \\
\text { your athletes, be on their } \\
\text { side both in their presence } \\
\text { and absence } \\
\text { - Be competent - display } \\
\text { your skills to gain your } \\
\text { athletes' admiration and } \\
\text { respect } \\
\text { Be neutral when placed in } \\
\text { difficult situations - don’t } \\
\text { choose sides until you } \\
\text { have all the facts } \\
\text { Being } \\
\text { reliable/consistent/predicta } \\
\text { ble - if you cancel or fail } \\
\text { to follow through will } \\
\text { create cracks in your } \\
\text { trustworthiness } \\
\text { Honour your promises - if } \\
\text { you make promises you } \\
\text { cannot keep your athletes }\end{array}$ & $\begin{array}{l}\text { - Map out individual } \\
\text { developmental plans for } \\
\text { each one athlete in your } \\
\text { team or squad (they need } \\
\text { to feel there is a plan for } \\
\text { them) - it motivates them } \\
\text { to stay and to work hard } \\
\text { - Have a programme of } \\
\text { performance based on } \\
\text { well-defined and mutually } \\
\text { agreed goals } \\
\text { - Make athletes' committed } \\
\text { to team’s goals } \\
\text { - Create opportunities for } \\
\text { development/advancemen } \\
\text { t } \\
\text { - Involve them in the } \\
\text { coaching process by } \\
\text { - Asking them what do } \\
\text { they need to be more } \\
\text { effective } \\
\text { - Asking them what will it } \\
\text { make them more } \\
\text { committed } \\
\text { - Communicate - make } \\
\text { effort to continually } \\
\text { exchange information } \\
\text { - Be open; openness is } \\
\text { reciprocated } \\
\text { - Offer information; show } \\
\text { you have nothing to hide, }\end{array}$ & $\begin{array}{l}\text { - Work together through } \\
\text { well-co-ordinated actions } \\
\text { - Lead/follow by example } \\
\text { - Improve communication } \\
\text { - "Simple communication” } \\
\text { is best and more impactful } \\
\text { - Ensure all members in the } \\
\text { team/squad know one } \\
\text { another (group spirit) } \\
\text { - Clarify roles and reinforce } \\
\text { rules } \\
\text { - Explain consequences if } \\
\text { rules are not met } \\
\text { - Meet regularly } \\
\text { - Address issues quickly } \\
\text { - Be well prepared for } \\
\text { training/competition } \\
\text { (mentally and physically) } \\
\text { - Create an environment } \\
\text { that is positive, engaging, } \\
\text { motivating, creative and } \\
\text { innovative } \\
\text { - Make an impression by } \\
\text { showing your competency } \\
\text { and expertise } \\
\text { - Create a friendly and } \\
\text { supportive environment } \\
\text { - Provide structure, } \\
\text { challenge and organisation } \\
\text { - instil a hard work ethos } \\
\text { - Show flexibility and }\end{array}$ \\
\hline
\end{tabular}




\begin{tabular}{|c|c|c|}
\hline 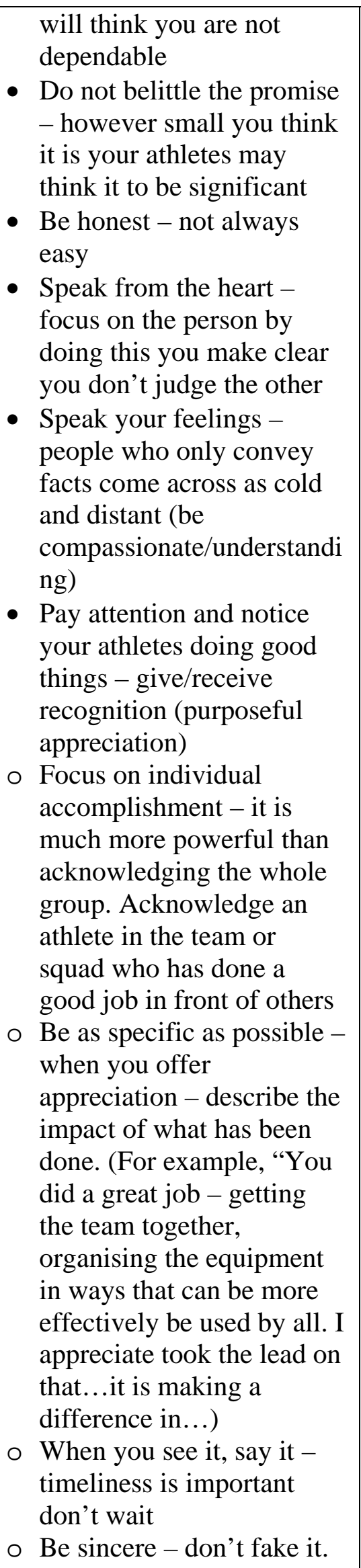 & $\begin{array}{l}\text { don’t omit, mask } \\
\text { - Listen and learn from } \\
\text { your athletes } \\
\text { - Need to be seen to take } \\
\text { action, making changes to } \\
\text { improve, prioritising } \\
\text { - Ensure responsibilities } \\
\text { (roles and rules or } \\
\text { expectations) are clearly } \\
\text { defined } \\
\text { - Spell the benefits of } \\
\text { staying with you (coach) } \\
\text { - Make sure everyone } \\
\text { knows is valued and } \\
\text { understood } \\
\text { - Commitment and } \\
\text { responsibility are } \\
\text { associated - it is both } \\
\text { coach and athlete’s } \\
\text { responsibility to make } \\
\text { things better/resolve } \\
\text { issues - this can be } \\
\text { achieved with continuous } \\
\text { dialogue and working } \\
\text { hard for improvement }\end{array}$ & $\begin{array}{l}\text { adaptability (adopt a } \\
\text { flexible management } \\
\text { style) } \\
\text { • Display responsiveness } \\
\text { - Clarify and recap the goals } \\
\text { each individual } \\
\text { wants/needs to accomplish } \\
\text { - Promote individual goals } \\
\text { - Promote team goals and } \\
\text { make sure everyone } \\
\text { knows } \\
\text { - Celebrate every success } \\
\text { (large and small) } \\
\text { - When “failure”- don’t see } \\
\text { it as liability but as a } \\
\text { learning opportunity } \\
\text { • Exhibit, and expect from } \\
\text { each athlete, responsive, } \\
\text { patient, determined, } \\
\text { driven, ambitious, } \\
\text { enthusiastic, disciplined } \\
\text { and focussed behaviours. }\end{array}$ \\
\hline
\end{tabular}


For more information, go to www.tandemperformance.com 